\title{
Collapse Time Analysis of Multi-Story Structural Steel Buildings
}

\author{
Robert M. Korol ${ }^{1, *}$, K.S. Sivakumaran ${ }^{2}$ and Frank R. Greening ${ }^{3}$ \\ ${ }^{I}$ Department of Civil Engineering, McMaster University, Hamilton, Ontario, Canada L8S 4L7 \\ ${ }^{2}$ Department of Civil Engineering, McMaster University, Hamilton, Ontario, Canada L8S 4L7 \\ ${ }^{3}$ CTS North America, Kincardine, Ontario, Canada N2Z $2 Y 7$
}

\begin{abstract}
Until recently, the progression and time of collapse of structures has not been a primary objective of the structural engineering profession. However, such events are likely to be of major interest in high rise building situations where a fire-initiated failure takes place, or where a controlled demolition is to be implemented. The paper attempts to shed light on this problem and to develop velocity profiles during a collapse event, also potentially important, especially in built-up areas. Because of the complex nature of both the structural system and the process of collapse, analysis methods need to be simplistic, which are yet realistic and are easily understood by designers and code writers of the nature and cause of a building collapse. The objective of this paper is to shed light on this problem by employing the most basic equations of Newton's laws of motion. A formulation of the problem of a building frame of $\mathrm{N}$ stories, subjected only to gravity loading is postulated that involves an analysis employing a generic one-dimensional discrete model of progressive collapse. The supporting elements within its $\boldsymbol{n}$ th story are suddenly degraded by whatever cause, with the velocity and time steps calculated. Several design scenarios are presented for the columns with prescribed energy dissipation properties ascertained at any level, thus allowing the motion to be determined in accordance with the known equations of energy and momentum. An example 10-story structure is proposed to illustrate the method, in which the column designs, utilizing square hollow sections and $\mathrm{W}$-shapes, are governed by a combination of dead, live and wind loads. For the 6 designs postulated involving tubular columns alone, and with sequential removal of columns in each of the 10 stories, it was found that progressive collapse was arrested in $90 \%$ for such hypothetical scenarios. For the other 10\%, global collapse times exceeded that of free-fall by 57 to $228 \%$.
\end{abstract}

Keywords: Multi-story steel frame, progressive collapse, collapse time, energy methods, motion arrest.

\section{INTRODUCTION}

The progression and time of collapse of structures has not been a topic of primary interest of the structural engineering profession, because engineers are trained to prevent such outcomes and regard failures as being a lesson of what to avoid rather than to conceive of its occurrence as a forensic event worthy of further investigation. For example, a fireinitiated failure within a particular story of a high rise building leading to its total demise raises questions about the design, about the combustibles contributing its fire load, and about the protection provided to the steel structure itself. Because of the complex nature of both a structural system, and the process of fire spread, its intensity, and the subsequent weakening of individual components during such an event, simplifications need to be made that are realistic and which are easily understood by designers and code writers of the nature and cause of a building collapse. Another aspect concerns those who are in the business of controlled demolitions. What is the best way to bring

\footnotetext{
*Address correspondence to this author at the Department of Civil Engineering, McMaster University, Hamilton, Ontario, Canada L8S 4L7; Tel: 905 525-9140 Ext, 24847; Fax: 905 529-9688;

E-mail:korol@mcmaster.ca
}

down a building, minimize the cost, ensure minimal spread of its collapse footprint and avoid the embarrassment of unanticipated motion arrest? Time of collapse and a prediction of velocity profiles during the event may also be of importance in built-up areas. The objective of this paper is to examine this problem by employing the most basic equations of Newton's laws of motion. Our intention is to examine the issue of building collapses to provide a forensic addition to tools already well-known, i.e. tests on material strength and ductility, signs of faulty construction and costcutting measures, or on design weaknesses which may or may not have met code requirements. But another reason for focusing on such an approach is to support the work of demolition firms, hired to bring down buildings, economically, with minimal disruption, and with some assurance that overall collapse will indeed be achieved.

In particular, this paper examines the likelihood of global collapse with lower bounds on the time required to terminate such an event when it occurs. To appreciate the progressive collapse stages predicted to occur, velocity-time profiles are generated employing simple Newtonian mechanics principles. This study is intended to highlight the very significant energy dissipation capacity present in many multi-story building columns having slenderness ratios near 
the short column category of design. In the process of studying the collapse of World Trade Center twin towers 1 and 2, Bazant and several associates [1-3] portrayed column response under crushing loads as bending elements such as what fixed-end beams would experience under lateral loads. Such a model is believed to be a short-coming, especially when plate reinforcements on $\mathrm{H}$-shapes or box columns are employed.

Research carried out decades ago showed the efficacy of square tubes as structural members subjected to axial compression [4, 5]. However, it was not until the late 70's and 80's that the significance of plastic folding mechanisms as energy absorbing stages of crushing became apparent [69] with applications to the automotive industry. Investigations of both quasi-static and dynamic axial loads were performed during this time, the focus being to develop energy absorbers for safe outcomes in crash worthiness tests. Excellent summaries of previous research, together with an array of test results on axial crushing of stainless and high strength steel box sections were published in papers by DiPaolo, et al., [10] and Tarigopula, et al., [11], respectively. Of particular significance relative to our work, are test results on relatively long square steel tubes which possessed slenderness ratios roughly equivalent to the model core columns recently published by two of the authors [12].

Our approach is to consider a very simple structure, having columns designed according to principles consistent with the Load and Resistance Factor Design codes [13, 14] with realistic assumptions about their energy dissipation properties during a collapse event. Following a general formulation, a 10 -story building, the columns of which have been designed in accordance with different load combinations governing, is investigated for its ability to resist realistic gravity loading. Partial or total collapse states and the times taken to achieve such failure conditions are predicted, considering only the columns as energy dissipation elements. The various column sizes selected are considered as being representative of buildings whose design is governed by gravity load alone (live plus dead), by gravity plus moderate wind or earthquake loads, and, finally, by gravity and intense wind or earthquake loading. Since the roof and floor systems are not deemed to be involved in energy dissipation during the progression of collapses, storyby-story, our model only surmises what typical dead loading would be for the spans of a simple rectangular floor plan. In all our cases, it is assumed that the floor system is rigidly connected to the continuous columns, thus providing moment-frame action resistance.

\section{FORMULATION OF THE PROBLEM}

Consider a typical $N$-story building of height $H$ with floor and roof dimensions of A by B as shown in Fig. (1). Height $h_{i}$ is the clear distance at story $i$. The mass at floor level $i$ is designated to be $m_{i}$. It is postulated that a given story $n \leq N$ is suddenly degraded to a state of zero resistance due to some catastrophic event occurring in story $n$. The result is a
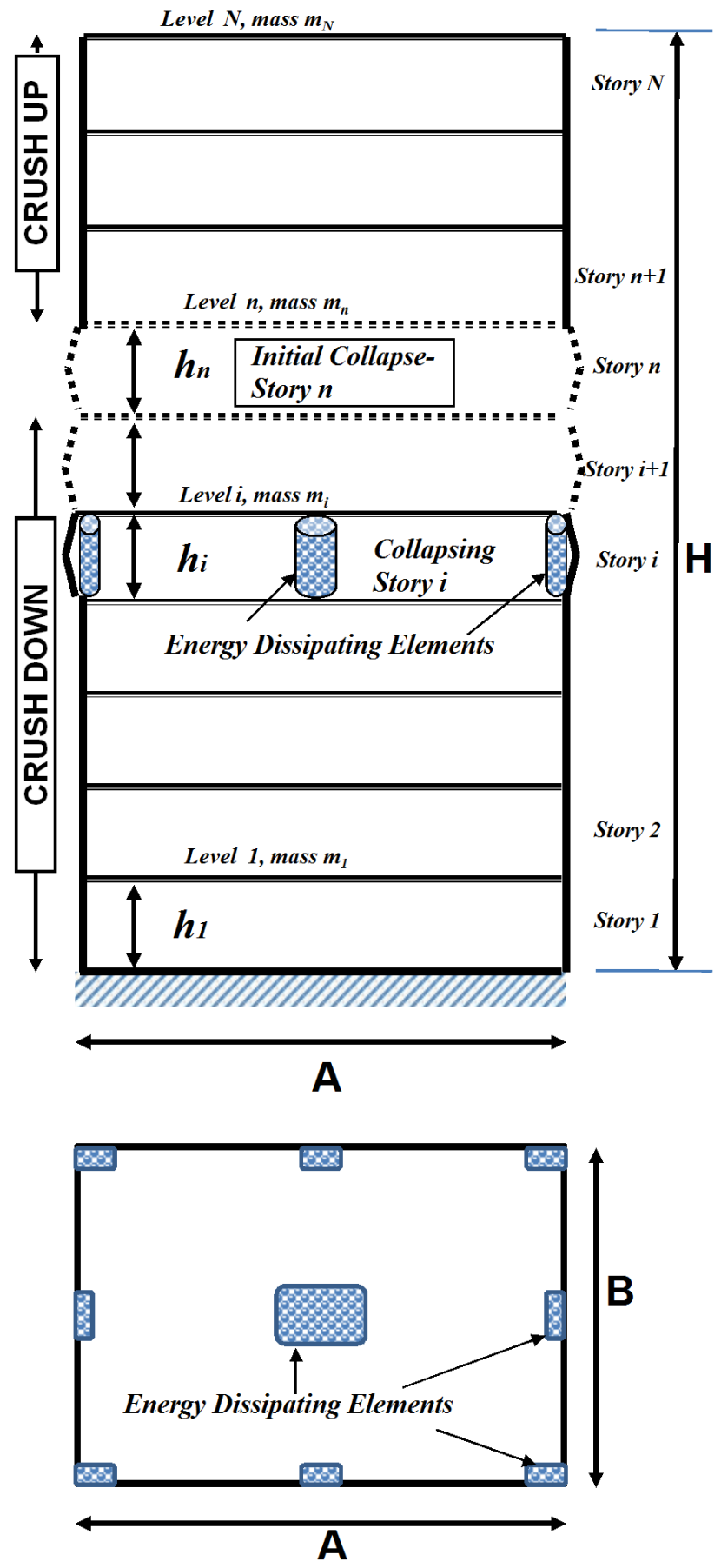

Fig. (1). Plan and Elevation of a Multi-Storey Building.

commencement of freefall motion of the rigid block above story $n$, until it impacts the floor level below (level $n-1$ ). Commensurate with the conservation of momentum principle, a sudden reduction in velocity is then expected due to the mass of the rigid block impacting the mass at level ( $n$ 1). While the consequent impulse, $\mathrm{F} \Delta \mathrm{t}$, occurring during the collision gives rise to a short interval of time, (during which a dense layer of crushed debris is forming), its estimation is beyond the scope of this study. However, if the resulting 
dynamic impact force exceeds the elastic limit of the resisting columns, plastic deformation will occur and is likely to continue to crush or bend the columns in the floor below until either the motion is stopped due to high energy capacity of the columns, or to continue with subsequent collision with the floor below (crush-down collapse). Depending on the mass of the moving crush-down front, its velocity, and the energy dissipation capacity of the columns in given stories, the crush-down front may be arrested or it may reach the ground level. If it does, then the columns in floors above level $n$ may begin to collapse, with the front moving upwards (crush-up collapse), until it is arrested or the roof mass comes to rest at the top of the debris pile. Note that there is no momentum exchange during the crush-up phase. This scenario of progressive collapse is consistent with the hypothesis described in the paper by Bazant and Verdue [2].

\section{Free Fall}

It is postulated that a given story $\boldsymbol{n}$ suddenly collapses. The result is a freefall motion of the stories above level $\boldsymbol{n}$ through height $\boldsymbol{h}_{\boldsymbol{n}}$. The stories above the initial collapse story $\boldsymbol{n}$ are intact but freefalling, as a rigid body and the total mass of that part of the building may be given as $M_{n}=\sum_{j=n}^{j=N} m_{j}$. Considering the motions of a freefalling object, the velocity of this body of mass at impact with the floor below (floor level $\mathrm{n}-1$ ) is given as $\mathrm{V}_{\mathrm{n}}^{\mathrm{F}}=\sqrt{2 g h_{n}}$, where $\mathrm{g}$ is the gravitational acceleration.

\section{Crush- Down Collapse}

As noted earlier, sudden collapse of the $\boldsymbol{n}^{\text {th }}$ story results in crush-down collapse of stories below it. Consider the crush-down collapse of the $\boldsymbol{i}^{\text {th }}$ story, where $\boldsymbol{i}<\boldsymbol{n}$. Since the stories above level $\boldsymbol{i}$ to level $\boldsymbol{n}$ have already collapsed and the block above the initial collapse story $\boldsymbol{n}$ is intact but freefalling, the total mass falling onto the $i^{\text {th }}$ level may be given as $M_{i+1}=\sum_{j=i+1}^{j=N} m_{j}$. The corresponding velocity at impact is designated herein as $\boldsymbol{V}^{\boldsymbol{F}}{ }_{i+1}$. Immediately thereafter, the velocity of crush-down is reduced due to the addition of floor mass $\boldsymbol{m}_{\boldsymbol{i}}$. The initial velocity of the combined mass given as $\boldsymbol{V}_{i}{ }_{i}$ may be obtained through the conservation of linear momentum equation as:

$$
\left[M_{i+1}+m_{i}\right] V_{i}^{I}=\left[M_{i+1}\right] V_{i+1}^{F}, \text { where } M_{i+1}=\sum_{j=i+1}^{j=N} m_{j}
$$

Assuming the crush-down front propagates through story $\boldsymbol{i}$, the final velocity $\boldsymbol{V}^{F}{ }_{i}$ of the total mass (before impact with floor $\boldsymbol{i}-1$ ) can be obtained through energy balance involving kinetic, potential and dissipation energy terms for crushing of the $i^{\text {th }}$ story as:

$$
1 / 2\left[M_{i+1}+m_{i}\right]\left(V_{i}^{F}\right)^{2}=1 / 2\left[M_{i+1}+m_{i}\right]\left(V_{i}^{I}\right)^{2}+\left[M_{i+1}+m_{i}\right] g h_{i}-E D_{i}
$$

$E D_{i}=$ the total energy dissipated by such elements in story $\boldsymbol{i}$, while $\boldsymbol{h}_{\boldsymbol{i}}$ represents the height of the crushing displacement within storey $\boldsymbol{i}$, understood as being less than the full story height. Note that in applying eqn (2), an imaginary solution for $\boldsymbol{V}^{F}{ }_{i}$ would indicate an arrest of collapse. Assuming there is no collapse arrest, then eqns (1) and (2) are applicable from the beginning of crush-down collapse potentially to the ground floor.

\section{Crush-Up Collapse}

If the crush-down front reaches the ground floor, then crush-up failures of stories $\boldsymbol{i}$ from $(\boldsymbol{n}+\mathbf{1})$ to $\boldsymbol{N}$ are likely to occur sequentially. Since subsequent collisions of story masses immediately above story $\boldsymbol{n}$ will occur with the rubble pile (assumed rigid), there will be no velocity loss at impact. As such, the initial velocity for crushing story $\boldsymbol{n + 1}$, namely, $\boldsymbol{V}_{n+1}^{I}$, will be equal to $\boldsymbol{V}_{1}^{{ }_{1}}$. Similarly, the initial velocity of crush-up story $i$, namely $\boldsymbol{V}_{i}^{I}$ will be equal to the final velocity of the story below, i.e. $\boldsymbol{V}^{\boldsymbol{F}}{ }_{i-1}$. The energy balance can then be applied to compute $\boldsymbol{V}^{\boldsymbol{F}}{ }_{i}$ as;

$$
1 / 2\left[M_{i}\right]\left(V_{i}^{F}\right)^{2}=1 / 2\left[M_{i}\right]\left(V_{i}^{I}\right)^{2}+\left[M_{i}\right] g h_{i}-E D_{i}
$$

$\boldsymbol{M}_{\boldsymbol{i}}$ is the total mass of the floors above story $\boldsymbol{i}$ given as $M_{i}=\sum_{j=i}^{j=N} m_{j}$, while $\boldsymbol{E D}_{\boldsymbol{i}}$ is the total energy dissipated by such elements in story $\boldsymbol{i}$. The calculation is repeated until finally the roof mass $\boldsymbol{m}_{N}$ comes to rest at the top of the debris pile (total collapse of the structure), or until a partial crush-up failure occurs, indicated by an imaginary final velocity $\boldsymbol{V}^{F_{i}}$ of a collapsing story $i$. As a matter of fact, as explained in the next section, in the event of collapse arrest the height of partially collapse story $\boldsymbol{i}$ can be established by assigning $\boldsymbol{V}^{F_{i}}=0$.

\section{ENERGY DISSIPATION ELEMENTS}

In the paper by Bazant and Zhou [1], the authors identify various ways in which steel columns can fail and then progress to a total crushed state. They considered a 3-hinged buckling mode, arguing that such an assumption maximizes the plastic energy dissipation. They considered such as an assumption regardless of shape, location, or value of the effective non-dimensional slenderness ratio, $\lambda$ of the columns. That assumption may seem reasonable, and it likely is, for wide flange columns that are poorly supported at upper and lower floor levels while buckling about their minor axes. However, when square tubular members are employed, essentially fixed at each floor level, the effective slenderness ratio is significantly reduced to computational values roughly equivalent to those in axial crush tests undertaken by DiPaolo, et al., [10] and DiPaolo and Tom [15]. Indeed, their test programs on stainless and low carbon steel box columns consistently demonstrated pure axial crush failures as opposed to a mixed mode type that one might anticipate for $\lambda>0.15$ [16], when utilizing grooved end plates to prevent crimping, but having little capability of offering moment restraint at the ends.

\section{Tubular Steel Columns}

As presented later, the sample building considered in this paper utilizes square columns, for which the slenderness 
parameter $\lambda$ was computed to be at the very low end of the cut-off value for short to intermediate length columns [13] and hence such compression members could qualify as short columns, prone to axial crushing. As such an analysis based on tubular crushing may be appropriate when the tubular dimensions and effective lengths warrant it. Research done by Wierzbicki and Abramowicz [8] and later by Abramowicz and Jones [17] on both quasi-static and dynamic crushing of tubular members, is deemed to have relevance in estimating the energy dissipation of such columns during a story collapse event. From their analytical and experimental study, a formula was developed by Wierzbicki and Abramowicz [8] for the average crushing resistance, $\mathrm{P}_{\mathrm{m}}$, during which progressive stages of plate element folding, compressing, and sequential propagation occurred, until the member became totally squashed. The average crushing resistance, $P_{m}$ is given as: $P_{m}=9.56 \sigma_{y} t^{5 / 3}$ $\mathrm{c}^{1 / 3}$, where $\mathrm{t}$ and $\mathrm{c}$ represent thickness, and outer plate width dimensions, respectively, for squares, with $\sigma_{\mathrm{y}}$ being the yield stress. Although our very recent study on steel box columns exhibited somewhat higher crush strength values than is given by $\mathrm{P}_{\mathrm{m}}$ cited earlier [12], we opted to utilize the above expression due to the limited number of tests undertaken. Furthermore, a collapsing building frame may be subject to high levels of strain rate, thereby having the effect of raising the value of $\mathrm{P}_{\mathrm{m}}$. Notwithstanding such knowledge, the formula cited [8] was employed to represent the average crushing resistance for reasons both of simplicity and conservatism. Accordingly, the energy dissipation in each such tubular column in a storey $\boldsymbol{i}$ can be established as

$$
E D_{i}=\left[9.56 \sigma_{y} t_{i}^{5 / 3} c_{i}^{1 / 3}\right] h_{i}
$$

where $\boldsymbol{t}_{\boldsymbol{i}}$ and $\boldsymbol{c}_{\boldsymbol{i}}$ are thickness and outer plate width dimensions of a tubular column at story $\boldsymbol{i}$, respectively, while $\boldsymbol{h}_{\mathrm{i}}$ represents the corresponding height of the crushing displacement. The energy dissipation of stories with multiple tubular columns can then be established by summing the dissipation capacity of each one.

\section{W-Shaped Columns}

When $\mathrm{W}$-shaped sections are used, the radius of gyration about the minor axis of bending tends to be much smaller than is the case for closed sections for similar outer dimensions. As such, the effective non-dimensional slenderness ratio $\lambda$ will be significantly larger. And, if there is inadequate bracing provided in the minor axis direction, the effective length factor $\mathrm{K}$ will be larger than the value 0.5 , which Bazant and Zhou [1] employed. In this study, a conservative value of $\mathrm{K}=1$ (pin-ended) was employed for $\mathrm{W}$-shapes columns. Assuming such a condition, the energy dissipation in W-shaped columns will very conservatively be taken as that due to plastic hinge bending alone. Such a column tends to fold on itself with bending about its minor axis. As such, the energy dissipation in such columns is given by $\boldsymbol{E D}_{\boldsymbol{i}}=\pi \mathrm{Z}_{\mathrm{yi}} \sigma_{\mathrm{y}}$, where $\mathrm{Z}_{\mathrm{yi}}$ is the plastic section modulus about the $y$-axis of the steel section located at story $i$. The energy dissipation of stories with multiple W-shaped columns can be established by summing the energy dissipation capacity of each W-shaped steel column.

\section{EXAMPLE: PROGRESSIVE COLLAPSE OF A 10-STORY BUILDING}

To shed light on the effect that various parameters might have on the progressive collapse of a typical hi-rise building, this study considered the consequences of suddenly removing the columns of any of its stories and to calculate the progression of collapse following that story's demise. This study considers an idealized 10-story building. Each story is presumed to be of height $4.15 \mathrm{~m}$, with a clear floor to ceiling height of $3.65 \mathrm{~m}$, a value also used as the height of $\boldsymbol{h}_{\boldsymbol{i}}$ that accounts for debris story pile-up. Fig. (2) shows the plan of the building under consideration. The floors and roof are $\mathbf{A}=16.12 \mathrm{~m}$ by $\mathbf{B}=16.12 \mathrm{~m}$, i.e. squares in plan. The building is subjected to a dead load of $5.74 \mathrm{kPa}$, a live load of $2.87 \mathrm{kPa}$ and lateral loads. The energy dissipating elements under considerations are a combination of tubular columns and W-shaped columns. A common grade of steel
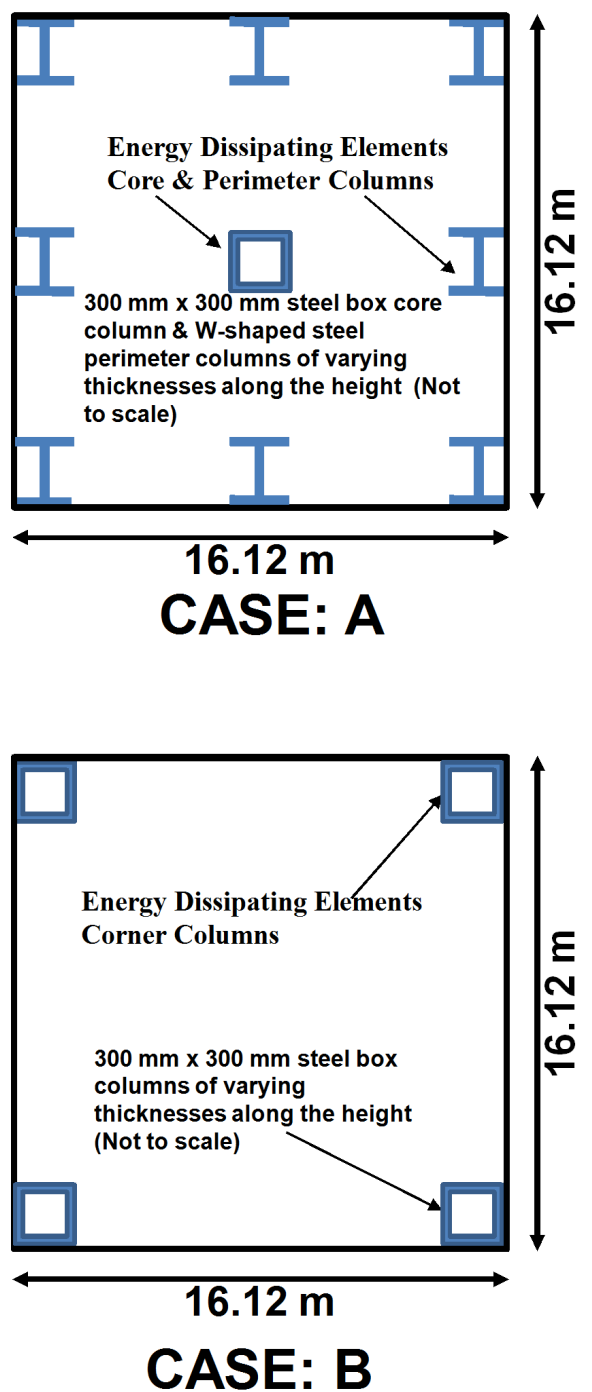

Fig. (2). Locations of Energy Dissipating Elements in Sample buildings- Case A and Case B. 
for square tubular sections is 350 class $\mathrm{H}$, which provides for a minimal degree of residual stresses from manufacturing $(\mathrm{H}$ $=$ hot formed), while the yield stress, $\sigma_{\mathrm{y}}$, is $350 \mathrm{MPa}$. All tubular steel sections under consideration are assumed to be 350 class $\mathrm{H}$. The wide flange columns under consideration are also assumed to be of an equivalent strength grade. In establishing the hypothetical sizes for such columns the following load and resistance factors were used which is based on Canadian standard CSA S16.1 [16]: dead load factor $=1.25$, live load factor $=1.50$, wind load factor $=1.50$, and the resistance factor $=0.9$. To work out the mass, it is assumed that the unfactored dead load of $5.74 \mathrm{kPa}$ applies, while the live load, devoid of occupants, was limited to $1 / 3^{\text {rd }}$ the $2.87 \mathrm{kPa}$ value (i.e. $20 \mathrm{lbs} / \mathrm{ft}^{2}$ ), thus giving a total value of $6.70 \mathrm{kPa}$. The mass, $\boldsymbol{M}$, per floor and roof level (made equal for simplicity), therefore computes as $\left[6.70 \times(16.12)^{2}\right.$ $\mathrm{x} 1000] / 9.81=177,500 \mathrm{~kg}$. As shown in Fig. (2), this study considered two different column layouts (energy dissipating elements).

\section{Case A - Single Tubular Steel Column Core and 8 W-shaped Perimeter Columns}

This case assumes a tubular steel column in the middle and eight W-shaped perimeter columns.

Tubular squares, $300 \times 300 \mathrm{~mm}$, were selected as the core column, while the thickness, $t_{i}$, of the column was assumed to increase from top to bottom in a linear incremental fashion. A similar approach has been made when we chose our $\mathrm{W}$-shapes, conceived as welded wide flanges so as to allow for flexibility in selecting sections. The central core column thicknesses varied, story-by-story, by $4 \mathrm{~mm}$ from top to bottom, thus providing cross sectional areas which would meet a given story's loading requirements. Meanwhile, the 8 perimeter columns were selected as W-shapes with a depth $\mathrm{d}=200 \mathrm{~mm}$. The flange width, its thickness, and that of the web were allowed to vary.

A total of 30 cases were analyzed for the configuration shown in Fig. (2) - Case A, which consists of 10 cases of three sets of designs designated herein as Design 1, 2 and 3. Design 1 represents the gravity-governing case, Design 2 represents severe lateral loading plus gravity, governing, while Design 3 represents very severe lateral loading plus gravity loads. As to the thickness of tubular core column, when gravity alone controls the design, the top to bottom thicknesses ranged from $4 \mathrm{~mm}$ in storey 10 down to $40 \mathrm{~mm}$ in the $1^{\text {st }}$ story. In the intermediate loading case, the thicknesses were chosen as $8 \mathrm{~mm}$ down to $44 \mathrm{~mm}$, while for the very severe lateral loading case they were chosen to vary from 12 to $48 \mathrm{~mm}$. With regard to the perimeter $\mathrm{W}$-shaped columns, for Design 1, the flange widths increase by $10 \mathrm{~mm}$ story-by-story, starting at $130 \mathrm{~mm}$ at the top, to $220 \mathrm{~mm}$ at the bottom level. For the intermediate and most severe loading cases (Designs 2 and 3), the pattern is the same add 10 and $20 \mathrm{~mm}$ respectively to the flanges. Meanwhile, the thicknesses increase from 8 to $26 \mathrm{~mm}$, then 10 to 28 and finally 12 to $30 \mathrm{~mm}$ as the original design shifts from light sizes to intermediate, and then to large. Finally, we need mention that the webs begin as $8 \mathrm{~mm}$ at the top to $17 \mathrm{~mm}$ at the bottom with increments of $1 \mathrm{~mm}$. Similar shifts of $1 \mathrm{~mm}$ were assumed when the more severe loading cases were identified.

\section{Case B - Four Corner Tubular Steel Columns}

Another possible design scenario is to assume that the floor area is sufficiently small that only corner columns are needed. For such a circumstance, we chose tubular squares at each corner of the building. Case B in Fig. (2) illustrates such a layout, in which the floor area is a square. To differentiate between the designs investigated, Cases A are those that involve single square core and 8 perimeter Wshape columns along the perimeter of the building, while Cases B involve 4 corner box section columns. Case B designs are further subdivided into two categories, namely, full axial crush energy dissipation $(\rho=1)$, and partial energy dissipation with only $50 \%$ effectiveness of the symmetric crush mode collapse case $(\rho=0.5)$. These latter cases take account of the likelihood that the crushing that involves a series of folds observed for short tubes [17], would be subjected to member plastic bending (asymmetric folding) as well, hence complicating the deformation pattern significantly. Until more square tube column tests are performed specific to having a range of low slenderness ratios; the $\rho=1 / 2$ efficiency value serves as an estimate only.

The thickness of tubular corner columns, when subject to gravity loading, only, governs the design (Design 1), the top to bottom thicknesses ranged from $4 \mathrm{~mm}$ in story 10 down to $40 \mathrm{~mm}$ in the $1^{\text {st }}$ story. In the intermediate loading case involving reasonably severe lateral loading plus gravity (Design 2), the thicknesses were chosen as $8 \mathrm{~mm}$ down to 44 $\mathrm{mm}$, while for the very severe lateral loading case (Design 3) they were chosen to vary from 12 to $48 \mathrm{~mm}$.

\subsection{Comparison of Energy Dissipation Models}

Table 1 gives the values of energy dissipation for columns within a given story based upon Cases A and B, with Designs 1, 2 and 3 noted for the scenario being investigated. Considering the Case A - Design 3- Story 10, a single core column $300 \times 300 \times 12 \mathrm{~mm}$, crushed over a distance of $\boldsymbol{h}_{\boldsymbol{i}}=3.65 \mathrm{~m}$ provides an energy dissipation value, $\boldsymbol{E D}_{\boldsymbol{i}}=5142 \mathrm{kN}-\mathrm{m}$, whereas a single perimeter $\mathrm{W}$-shape column at the same level, calculated as $\pi Z_{y} \sigma_{y}$, (singlehinged case) gives a value of only $153.3 \mathrm{kN}-\mathrm{m}$ (350 MPa steel). Therefore, the total energy dissipation at this level is obtained as $5142+8 * 153.3=6369 \mathrm{kN}-\mathrm{m}$. Similarly, when the thickness of a core column is $48 \mathrm{~mm}$ (Case A - Design 3- Story 1), the energy dissipation values of the core and a single $\mathrm{W}$-shape are 51,831 and $963.9 \mathrm{kN}-\mathrm{m}$, respectively, giving a total energy dissipation capacity of 59,543 kN-m.

It's perhaps of interest to compare squash model energy results for the square tubular columns with those for which the 3 plastic hinge model of Bazant [1] would predict. Since the most slender wall thickness cases do not strictly qualify as plastic design members, we will examine cases for which 
Table 1. Energy Dissipating Capacity of a 10 Story Building

\begin{tabular}{|c|c|c|c|c|c|c|c|c|c|}
\hline \multirow{4}{*}{$\begin{array}{l}\text { Storey } \\
\text { Level }\end{array}$} & \multicolumn{3}{|c|}{$\begin{array}{l}\text { CASE A: Single square core and eight } \\
\text { perimeter W-columns }\end{array}$} & \multicolumn{6}{|c|}{$\begin{array}{l}\text { CASE B: Four corner box columns } \\
\text { ( } \rho \text { indicates the efficiency of energy dissipating elements, } \rho=0.5 \text { indicates } 50 \% \text { efficiency) }\end{array}$} \\
\hline & \multirow{2}{*}{$\begin{array}{l}\text { Design } 1 \\
\rho=1.0\end{array}$} & \multirow{2}{*}{$\begin{array}{c}\text { Design } 2 \\
\rho=1.0\end{array}$} & \multirow{2}{*}{$\begin{array}{c}\text { Design } 3 \\
\rho=1.0\end{array}$} & \multicolumn{2}{|c|}{ Design 1} & \multicolumn{2}{|c|}{ Design 2} & \multicolumn{2}{|c|}{ Design 3} \\
\hline & & & & $\rho=1.0$ & $\rho=0.5$ & $\rho=1.0$ & $\rho=0.5$ & $\rho=1.0$ & $\rho=0.5$ \\
\hline & (kN.m) & (kN.m) & (kN.m) & (kN.m) & (kN.m) & (kN.m) & (kN.m) & (kN.m) & (kN.m) \\
\hline 9 & 3510 & 6369 & 9928 & 10465 & 5232 & 20569 & 10285 & 33224 & 16612 \\
\hline 8 & 6369 & 9928 & 14134 & 20569 & 10285 & 33224 & 16612 & 48191 & 24096 \\
\hline 7 & 9928 & 14134 & 18952 & 33224 & 16612 & 48191 & 24096 & 65304 & 32652 \\
\hline 6 & 14134 & 18952 & 24353 & 48191 & 24096 & 65304 & 32652 & 84434 & 42217 \\
\hline 3 & 30318 & 36830 & 43878 & 105480 & 52740 & 128358 & 64179 & 152998 & 76499 \\
\hline 2 & 36830 & 43878 & 51452 & 128358 & 64179 & 152998 & 76499 & 179339 & 89669 \\
\hline 1 & 43878 & 51452 & 59543 & 152998 & 76499 & 179339 & 89669 & 207326 & 103663 \\
\hline
\end{tabular}

( $\rho$ indicates the efficiency of energy dissipating elements, $\rho=0.5$ indicates $50 \%$ efficiency).

$\mathrm{t}=12 \mathrm{~mm}$ and $\mathrm{t}=48 \mathrm{~mm}$ as the extremes that do. (Note that our analysis assumes only a mid-height hinge, so the value would $1 / 2$ the above value). When equivalent tributary areas are accounted for, the energy dissipation for $\mathrm{W}$-shaped columns amounts to only $16 \%$ (or $8 \%$ for our assumption) of crush energy dissipation. A similar situation exists when we examine differences at lower levels. Thus, when the thickness of a core column is $48 \mathrm{~mm}$, the energy dissipation values are 51,831 and 5,141 $\mathrm{kN}-\mathrm{m}$ (or 2,570 kN-m) respectively for equal tributary area resistance. It is obvious that there are major differences, then, between the two systems of support, both of which were designed to meet the same loading requirements.

Case B considers four corner columns having the same dimensions as the core column considered in Case A. Thus, when full energy dissipation $(\rho=1)$ is considered the total energy dissipation is four times that dissipated in the core column. Consider the Case B - Design 3- Story 10. A single corner column $300 \times 300 \times 12 \mathrm{~mm}$, crushed over a distance of $\boldsymbol{h}_{\boldsymbol{i}}=3.65 \mathrm{~m}$ provides an energy dissipation value, $\boldsymbol{E} \boldsymbol{D}_{\boldsymbol{i}}=$ $5142 \mathrm{kN}-\mathrm{m}$, therefore giving a total energy dissipation capacity in story 10 of $4 \times 5142=20,569 \mathrm{kN}-\mathrm{m}$. When partial energy dissipation with only $50 \%$ effectiveness $(\rho=0.5)$ is considered, the corresponding energy dissipation capacity is $10,285 \mathrm{kN}-\mathrm{m}$.

\section{RESULTS}

In our calculations, we assume that a catastrophic event (such as intense fire) occurring at story $\boldsymbol{n}$ negates the capacity of the supporting columns to sustain load. As such, roof and floor levels above come crashing down in freefall for a distance $\boldsymbol{h}_{\boldsymbol{n}}=3.65 \mathrm{~m}$, providing an initial velocity of $8.46 \mathrm{~m} / \mathrm{s}$.

\section{Velocity and Collapse Time Results for Case A Building Frames}

Calculations employing the equations listed in Section 2 were performed for total loss of strength of the columns in all 10 stories for 3 sets of combinations of single square tube core columns and their perimeter column counterparts for the dimensional cross section changes at every story. Fig. (3) indicates the velocity differences experienced for a given design of the structure when a particular story is suddenly degraded. In Fig. (3), Design 1, representing the lightest columns, illustrates the variations that can occur when global collapse is the final state of the structure. For instance, removal of story 1 results in a smooth increase in velocity throughout the progressive crush-up collapse event. On the other hand, a sudden localized collapse of story 10 results in saw-tooth motion due to the transfer of momentum story-bystory as the upper block crushes downwards until total collapse occurs. Meanwhile, sudden degradation of story 5 is a mix of downward crushing with consequent momentum exchanges, followed by crush-up to the roof without changes of momentum being experienced.

To illustrate such motions with respect to time, two design sets were selected. Fig. (4a) shows results of the same cases used in Fig. (3), i.e. representing the response of $8 \mathrm{H}$ shaped perimeter columns with a single box column at the center (Fig. (2) - Case A) for a location for which gravity forces alone govern the design. The plots are very similar but have the advantage of indicating the times of incremental 


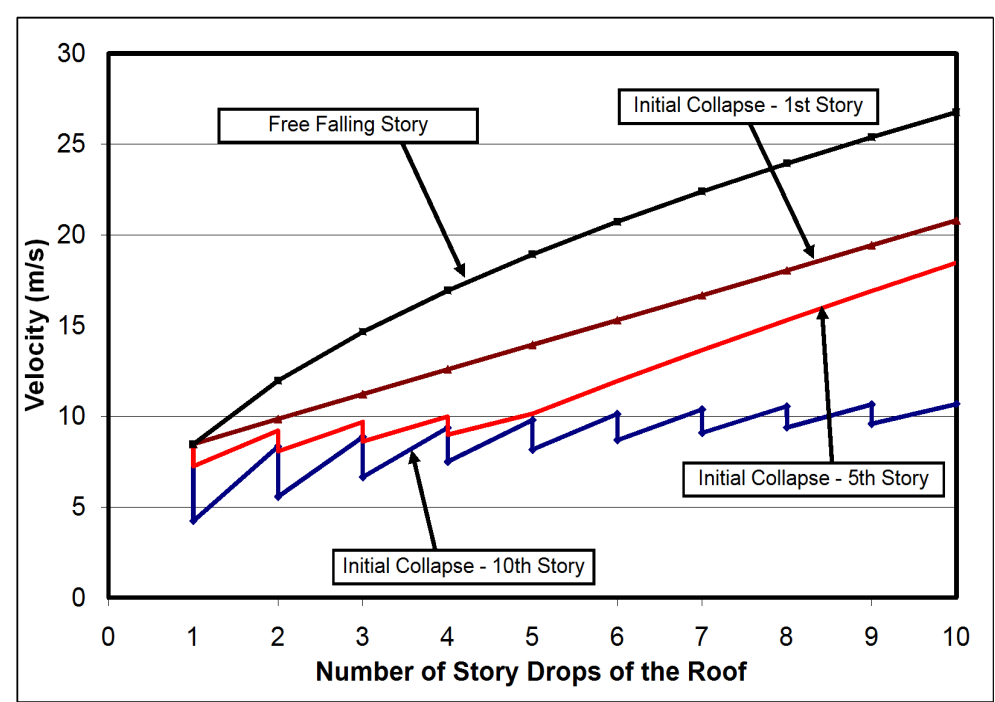

Fig. (3). Velocity with Number of Storey Drops of the Roof.

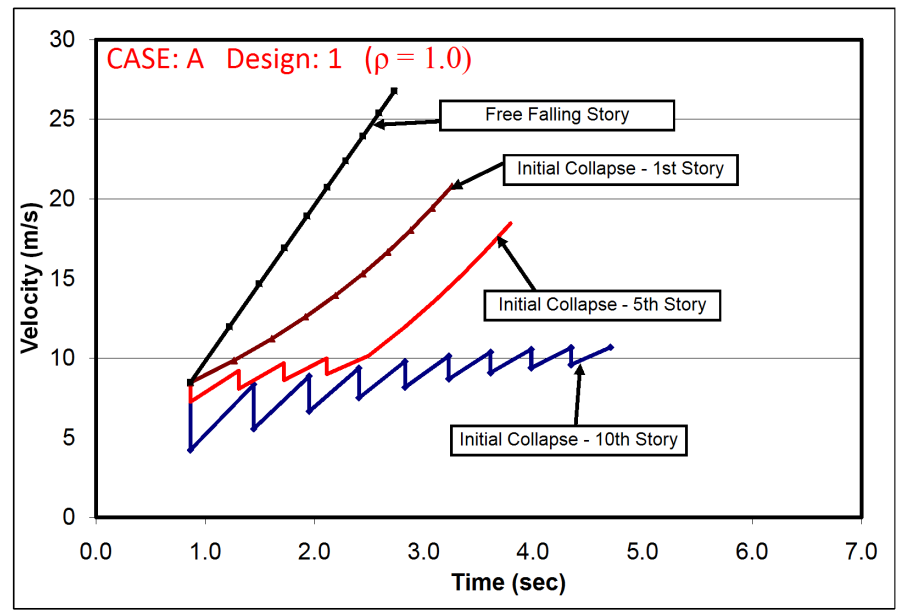

Fig. (4a). Motion History - CASE: A - Design 1

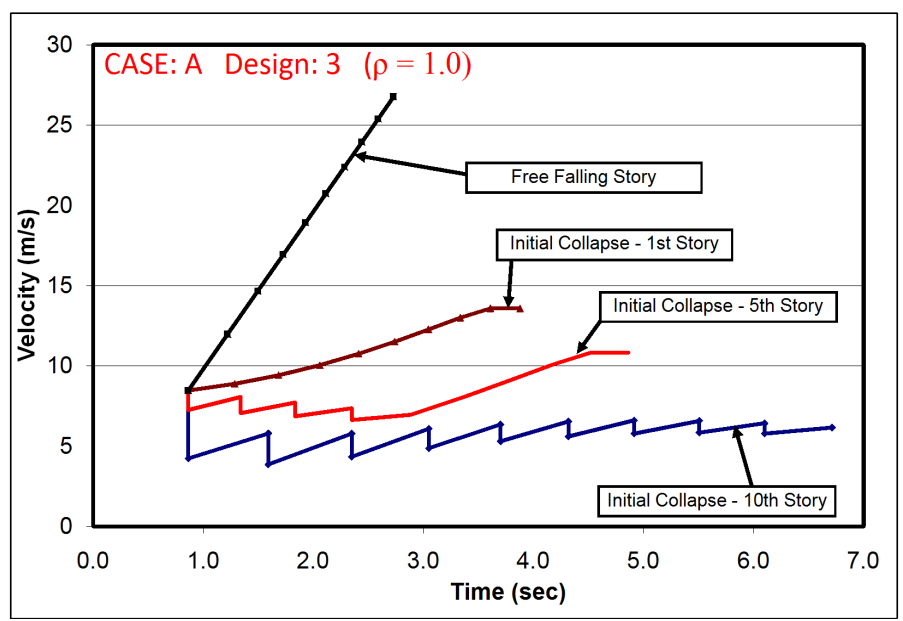

Fig. (4b). Motion History - CASE: A - Design 3

Fig. (4a). Motion History - CASE: A - Design 1 (4b) Motion History - CASE: A - Design 3.

and final collapse. Fig. (4b) shows the response of Design 3 columns, i.e. having the same layout as (4a) but where the design is governed by a severe lateral load and gravity combination. It will be noted that for these cases the velocities are significantly less, while the collapse times are significantly more than for their Design 1 counterparts. Results of interest are presented for each of the Case A data sets as follows. 


\section{[a] Design 1}

Removal of the columns in story 10 , and the subsequent progression of collapse story-by-story, resulted a total time of collapse of 4.704 seconds (Table 2), and a final velocity of $10.69 \mathrm{~m} / \mathrm{s}$. When bottom story strength is suddenly withdrawn, the time of collapse and final velocity of the roof striking the rigid rubble pile are 3.254 seconds and 20.80 $\mathrm{m} / \mathrm{s}$, respectively. The reason for such a difference is that crush-down involves momentum transfers as stories impact with one another. When the roof strikes the $10^{\text {th }}$ floor, the initial velocity commencing crushing of the $9^{\text {th }}$ story columns is only $4.23 \mathrm{~m} / \mathrm{s}$ as opposed to $8.46 \mathrm{~m} / \mathrm{s}$ (freefall for $3.65 \mathrm{~m}$ ). Although diminishing velocity differences (during momentum transfer) continue all the way down, initial kinetic energy values while increasing, do so more slowly than if these collisions were ignored. Its saw-tooth pattern of collapse motion, shown in Fig. (4a), is indicative of momentum transfers at every story.

Contrast this case with the crush-up scenario, in which the bottom story is removed and the $2^{\text {nd }}$ story columns must offer resistance without the benefit of momentum transfer. As such, they are subjected to an initial velocity of $8.46 \mathrm{~m} / \mathrm{s}$. The large mass, (mass of nine floors above), together with a similarly large potential energy term overpowers that story's energy dissipation ability, resulting in an ever-increasing velocity until collapse. The plot for this scenario is a smooth curve, as noted in the figure.

Other cases involve crush-down followed by crush-up. As expected, the collapse times and final velocities fall inbetween these two extremes. An intermediate situation would be the sudden demise of story 5 . Note that it has a saw-tooth pattern during crush-down, followed by a smooth response during crush-up.

Of particular interest is a comparison with freefall time of the roof striking the debris pile at ground level. The assumed $36.5 \mathrm{~m}$ fall would take place in 2.728 seconds. As such, our results indicate collapse times from 19.3 to $72.4 \%$ higher than freefall. The freefall case shows that there is a significant difference with the story 10 scenario, especially.

\section{[b] Design 2}

Although plots for this intermediate design are not shown (for reasons of conciseness), corresponding collapse times are given in Table 2. For Design 2, lower velocities and longer collapse times were noted relative to their counterparts shown in Fig. (4a), because of the heavier columns employed. For this set of runs, the collapse times ranged from 27.8 to $95.3 \%$ higher than freefall, with an intermediate case, namely, removal of story 5 , found to be $52.5 \%$ higher.

\section{[c] Design 3}

This set of runs represents cases in which the columns are sufficiently robust that nearly every conceivable conventional loading case can be resisted (extraordinary fire loading excluded). In these cases, the maximum velocity, even for story 1 failing first, resulted in a maximum velocity of $13.59 \mathrm{~m} / \mathrm{s}$, in comparison with a freefall speed of 26.76 $\mathrm{m} / \mathrm{s}$. In this case of $1^{\text {st }}$ story removal, collapse time occurs in 3.877 sec., which is $42.2 \%$ more than that for freefall. The intermediate case of story 5 gave a time of $4.86 \mathrm{sec}$., while

Table 2. Impact of Energy Dissipating Elements on the Total Collapse Times of a 10-Story Building

\begin{tabular}{|c|c|c|c|c|c|c|c|c|c|}
\hline \multirow{4}{*}{$\begin{array}{c}\text { Initial } \\
\text { Collapse } \\
\text { Storey }\end{array}$} & \multicolumn{3}{|c|}{$\begin{array}{l}\text { CASE A: Single square core and eight } \\
\text { perimeter W-columns }\end{array}$} & \multicolumn{6}{|c|}{$\begin{array}{l}\text { CASE B: Four corner box columns } \\
\text { ( } \rho \text { indicates the efficiency of energy dissipating elements, } \rho=0.5 \text { indicates } 50 \% \text { efficiency) }\end{array}$} \\
\hline & \multirow{2}{*}{$\begin{array}{c}\text { Design } 1 \\
\rho=1.0\end{array}$} & \multirow{2}{*}{$\begin{array}{c}\text { Design } 2 \\
\rho=1.0\end{array}$} & \multirow{2}{*}{$\begin{array}{c}\text { Design } 3 \\
\rho=1.0\end{array}$} & \multicolumn{2}{|c|}{ Design 1} & \multicolumn{2}{|c|}{ Design 2} & \multicolumn{2}{|c|}{ Design 3} \\
\hline & & & & $\rho=1.0$ & $\rho=0.5$ & $\rho=1.0$ & $\rho=0.5$ & $\rho=1.0$ & $\rho=0.5$ \\
\hline & (Seconds) & (Seconds) & (Seconds) & (Seconds) & (Seconds) & (Seconds) & (Seconds) & (Seconds) & (Seconds) \\
\hline 10 & 4.704 & 5.329 & 6.712 & $3.433(7)^{*}$ & $7.451(1)^{*}$ & $1.559(9)^{*}$ & $6.902(5)^{*}$ & $1.130(9)^{*}$ & $2.264(8)^{*}$ \\
\hline 9 & 4.424 & 4.962 & 6.124 & $2.812(7)^{*}$ & $6.777(1)^{*}$ & $1.663(8)^{*}$ & $5.380(4)^{*}$ & $1.239(8)^{*}$ & $2.616(7)^{*}$ \\
\hline 8 & 4.226 & 4.711 & 5.728 & $2.223(6)^{*}$ & $6.207(1)^{*}$ & $1.584(7)^{*}$ & $4.616(4)^{*}$ & $1.275(7)^{*}$ & $2.642(6)^{*}$ \\
\hline 7 & 4.066 & 4.508 & 5.404 & $1.965(5)^{*}$ & $5.678(1)^{*}$ & $1.516(6)^{*}$ & $3.973(3)^{*}$ & $1.279(6)^{*}$ & $2.542(5)^{*}$ \\
\hline 6 & 3.925 & 4.329 & 5.121 & $1.870(5)^{*}$ & $5.187(1)^{*}$ & $1.454(5)^{*}$ & $3.571(3)^{*}$ & $1.269(5)^{*}$ & $2.412(4)^{*}$ \\
\hline 5 & 3.792 & 4.162 & 4.862 & $1.685(4)^{*}$ & 6.647 & $1.401(4)^{*}$ & $3.127(2)^{*}$ & $1.254(4)^{*}$ & $2.286(3)^{*}$ \\
\hline 4 & 3.662 & 3.998 & 4.615 & $1.564(3)^{*}$ & 5.936 & $1.357(3)^{*}$ & $2.853(1)^{*}$ & $1.238(3)^{*}$ & $2.173(2)^{*}$ \\
\hline 3 & 3.530 & 3.833 & 4.370 & $1.478(2)^{*}$ & 5.325 & $1.320(2)^{*}$ & $2.683(1)^{*}$ & $1.221(2)^{*}$ & $2.075(1)^{*}$ \\
\hline 2 & 3.394 & 3.663 & 4.125 & $1.414(1)^{*}$ & 4.782 & $1.288(1)^{*}$ & $3.993(4)^{*}$ & $1.206(1)^{*}$ & $2.235(3)^{*}$ \\
\hline 1 & 3.254 & 3.487 & 3.877 & $1.555(2)^{*}$ & 4.285 & $1.377(2)^{*}$ & 8.945 & $1.266(2)^{*}$ & $2.504(3)^{*}$ \\
\hline
\end{tabular}

( $\rho$ indicates the efficiency of energy dissipating elements, $\rho=0.5$ indicates $50 \%$ efficiency).

$*$ indicates partial collapse and the number within bracket shows the story which arrested the progressive collapse. 
that in which story 10 suddenly fails, is $6.712 \mathrm{sec}$., an increase of $145.8 \%$ longer than freefall.

It is useful to compare the influence of the various design cases on total collapse times. Fig. (5) indicates that higher strength columns tend to delay progressive collapse to a considerable degree compared with lowest strength cases as expected. As noted earlier, the higher the story that degrades to a state of localized failure, the longer will be the structure's collapse time.

\section{Collapse Time and Velocity Results for Case B Building Frames}

It is informative to consider a couple of assumptions involving the efficiency with which relatively short columns of hollow square cross section offer resistance during crushing (Case B of Fig. (2)). A possible non-conservative case would be to assume that the Wierzbicki and Abramowicz formula, $\mathrm{P}_{\mathrm{m}}=9.56 \sigma_{\mathrm{y}} \mathrm{t}^{5 / 3} \mathrm{c}^{1 / 3}$ is fully applicable to columns that are short, but not in the category of stubs. On the other hand, dynamic loading research done later by the Abramowicz and Jones [17], modified the formula, such that the calculated resistances are about $36 \%$ higher than that reported in the earlier study and is more consistent with our McMaster study [12]. As such, it is reasonable to assume an upper range of average resistance for the four column layout equal to $\rho \mathrm{P}_{\mathrm{m}}$, where the efficiency factor $\rho=1.0$. However, to account for the uncertainty associated with the complex bending and crushing that would likely occur (as noted earlier), we also investigated the circumstance where $\rho=0.5$.

\section{Fully Effective Corner Columns}

Fig. (6) shows velocity- time plots for the Design 1 cases (lightest column design) in which stories 1,5 and 10 suddenly degrade and fail. Note that the time is described as "to Arrest", denoting partial collapse of the structure only, i.e. global collapse does not occur, for any of these scenarios.
Removal of story 10 will result in arrest during crush of the $7^{\text {th }}$ story, with termination after occurring after 3.433 seconds (Table 2). In the case of story 5, the motion arrests in adjacent story 4 after only 1.685 sec., while in the case of 10 (crush-up), collapse is arrested in story 2 after 1.555 seconds. Analyses were performed as well for Designs 2 and 3 for completeness for $\rho=1.0$ cases. Needless to say, the heavier column sections were even more resistant to collapse and were found to arrest in the adjacent story in every case. Times of arrest ranged from a high of $1.663 \mathrm{sec}$ (Case B Design 2 with $\rho=1.0$ - initial collapse story 9), to a low of 1.130 seconds (Case B - Design 3 with $\rho=1.0$ - initial collapse story 10$)$.

\section{Partially Effective Corner Columns}

In these cases, the effective resistance factor $\rho$ was taken as 0.5 , with actual values of energy dissipation given in Table 1. With the corner columns only $50 \%$ effective, the question of whether a given scenario would lead to total collapse or arrested motion was considered to be of significant interest, for curiosity reasons if nothing else. As such, a repeat of 30 computer runs was performed for designs 1, 2 and 3, each with one of the 10 stories removed one-by-one. The corresponding results are given in Table $\mathbf{2}$.

For the light column cases (Design 1), it was found that half arrested, and the other half resulted in total collapse. Interestingly, each of stories $10,9,8,7$ and 6 crushed all lower stories except story 1 with motion arrested without contacting the debris pile. Times of arrest ranged from 7.451 to 5.187 seconds. Meanwhile, collapse times for stories 1 through 5 ranged from a high of 6.647 (story 5 removed), to 4.285 seconds (story 1 removed).

For Design 2 cases (intermediate column sizes), only the demise of story 1 led to total collapse in $8.945 \mathrm{sec}$. All other cases resulted in arrested motion in stories two or more remote from the one that suffered the initial sudden failure. For example, local collapse of story 10 was arrested in story

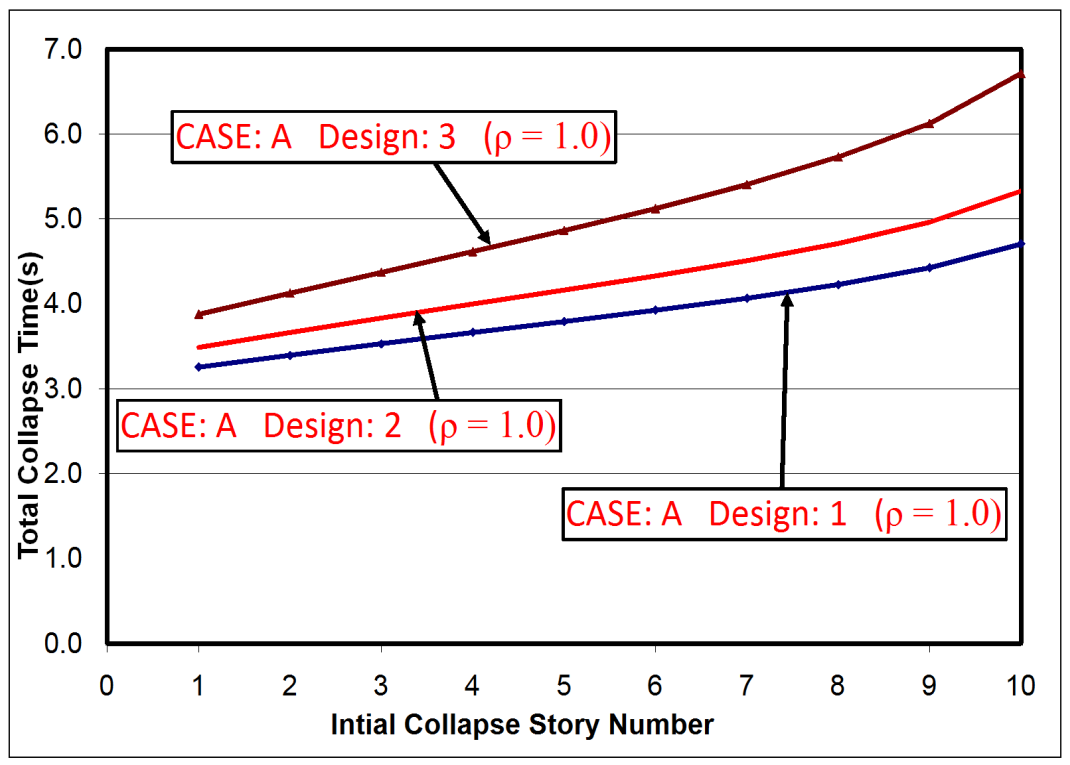

Fig. (5). Impact of Strength of Columns on the Total Collapse times. 


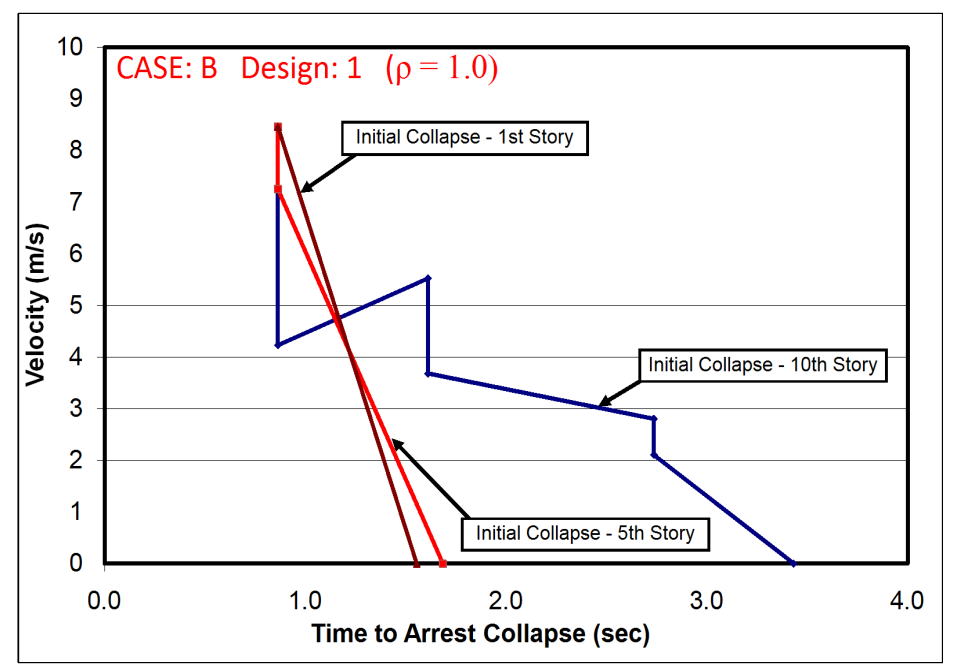

Fig. (6). Motion History to Arrest Collapse.

5, while story 3's loss of strength, resulted in arrest in story 1. Regarding the Design 3 scenarios (heaviest columns), collapse was arrested in every case, with motion terminated in the stories two levels remote from the one suffering initial failure. Fig. (7a, b, c) show the time to collapse or arrest plots for roof level velocity for stories 1,5 and 10 for the three sets of designs (light, intermediate and heavy). Not surprisingly, the collapse times increase, or, the arrest time decreases as the column sizes increase.

\section{DISCUSSION}

A summary of the totality of our investigation is given in Table 2. It shows that total collapse will occur when our 10story model structure utilizes W-shape perimeter columns with only a single hollow square core column dissipating most of the energy during the event. The collapse times for the scenarios studied were found to range from 19 to $146 \%$ longer than free-fall.

When more than one square continuous column is employed ( 4 or 2 equivalent), the results arouse curiosity to an even greater degree. Decelerations following the initial story free-fall were noted in every case during crush-down of the Case B scenarios. Although global collapses occurred for lower story removals in Design 1 cases (with $\rho=0.5$ ), arrests were also typical for the crush-up phase. But perhaps more significantly, only 6 out of a total of 60 cases actually resulted in total collapse. The remaining $90 \%$ only suffered a partial collapse. It should be mentioned that by ignoring the times during which the impulse-momentum equations are applicable (during collisions with individual stories), and the energy dissipation contributions of secondary structural and non-structural elements, that the results of our analysis represent lower bounds on collapse times, and exclude collapse cases which may indeed only suffer partially.

Up to the time of the 9-11 collapses, it had been assumed that steel framed buildings were inherently resistant to progressive collapse. As well, fire protection measures, if done properly, were presumed to nullify the need to embrace fire loading into the design of multi-story buildings. The a

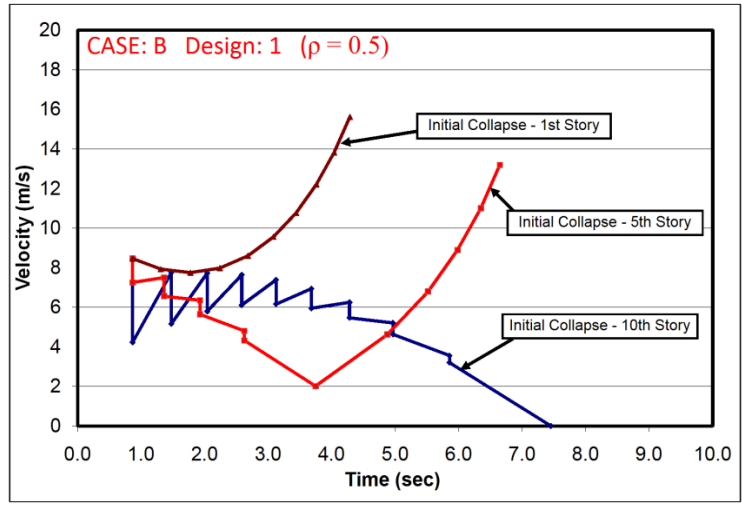

b
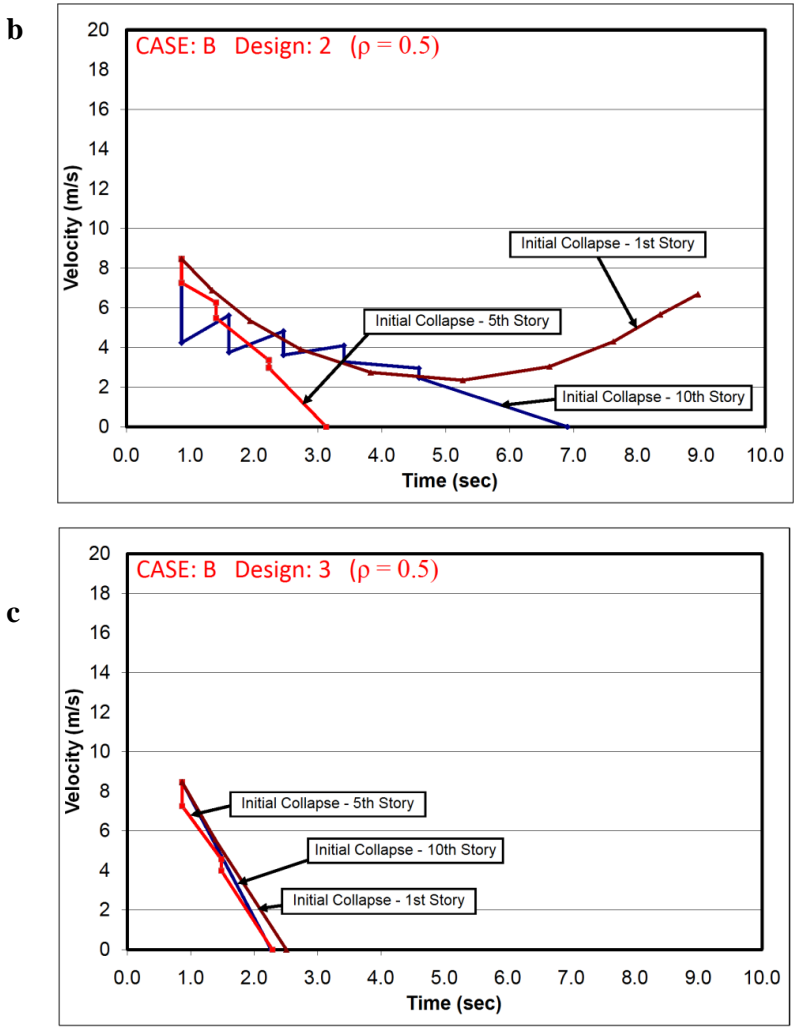

Fig. (7). Motion History to Collapse/Arrest. 
results of our study suggest that a new approach is needed to more fairly credit steel structures, especially those employing square tubular columns, or those H-shapes reinforced with flange tip-to-tip cover plates, to have an ability to withstand global collapse under conditions which render given stories a degree of strength degradation that will cause only localized collapse. Since our energy dissipation model employed information about the crushing of closed tubular members directed towards the automotive industry, we need evidence more pertinent to structural engineering designers. In this regard, it is obvious that experiments on short, to moderately short steel columns, tested to a complete crush state would yield useful information that would provide more confidence to architects and engineering design firms that indeed, steel framed hi-rise buildings are inherently safe if designed and constructed properly.

\section{REFERENCES}

[1] Z. P. Bazant, and Y. Zhou, "Why did the World Trade Center collapse? - simple analysis", J. Eng. Mech., vol. 128, no.1, pp. 2-6, with Addendum, March, no.3, pp. 369-370, 2002.

[2] Z. P. Bazant, and M. Verdure, "Mechanics of progressive collapse: learning from World Trade Center and building demolitions", $J$. Eng. Mech., vol. 133, no.3, pp. 308-319, 2007.

[3] Z. P. Bazant, J.-L. Le, F. R. Greening, and D. B. Benson, "What did and did not cause collapse of World Trade Center twin towers in New York?", J. Eng. Mech., vol.134, no.10, pp. 892-906, 2008.

[4] R. G. Redwood, R.G., "On the buckling of thin walled tubes under axial impact”, J. Royal Aero Soc.,Vol. 68, no.7, pp. 418-419, 1964.
[5] R. M. Korol, and A. N. Sherbourne, "Strength predictions of plates in uniaxial compression", J. Struct. Div., ASCE., vol. 98, pp. 19651986, 1972.

[6] S. R. Reid, and T. Y. Reddy, "Axially loaded metal tubes as impact energy absorbers", see L. Bevilacqua, R. Feijoo, and R. Valid, Eds, "Inelastic Behaviour of Plates and Shells" - IUTAM Symposium of Aug. 1985, Rio de Janeiro, Springer-Verlag, 1986, pp. 569-595.

[7] W. Abramowicz, and T. Wierzbicki, "A kinetic approach to crushing of shell structures", In $3^{\text {rd }}$ International Conference on Vehicle Structural Mechanics: Society of Automotive Engineers, Troy, USA, 1979, pp. 211-233.

[8] T. Wierzbicki, and W. Abramowicz, "On the crushing mechanics of thin-walled structures", J. Appl. Mech., vol. 50, no. 4A, pp. 727734, 1983.

[9] T. Wierzbicki and W. Abramowicz, "The mechanics of deep plastic collapse of thin-walled structures". In: T. Wierzbicki, and N. Jones, Eds, Structural failure, vol. 9. John Wiley, 1989, pp. 281-329.

[10] B. P. DiPaolo, P.J. M. Monteiro, and R. Gronsky, "Quasi-static axial crush response of a thin-wall, stainless steel box component", Int. J. Solids Struct., vol. 41, pp. 3730-3733, 2004.

[11] V. Tarigopula, M. Langseth, O. S. Hopperstad, and A. H. Clausen, "Axial crushing of thin-walled high-strength steel sections", Int. J. Impact Eng., vol. 32, pp. 847-882, 2006.

[12] R. M. Korol, and K.S. Sivakumaran (2011) "Energy Dissipation Potential of Square Tubular Steel Columns Subjected to Axial Compression", Int Rev Civil Eng (IRECE), vol. 2, no. 1, January 2011.

[13] AISC, Specification for Structural Steel Buildings, Chicago, 2005.

[14] CISC, Handbook of Steel Construction, 10th ed, Canadian Institute of Steel Construction, Markham, Ontario, Canada, 2010.

[15] B.P. DiPaolo and J.G.Tom, "Study on an axial crush configuration response of thin wall box components: The quasi-static experiments", Int. J. Solids Struct., vol. 43, pp.7752-7775, 2006.

[16] CSA, S16-09 Design of Steel Structures, Canadian Standards Association, Mississauga, Ontario, Canada, 2009.

[17] W. Abramowicz, and N. Jones, "Dynamic progressive buckling of circular and square tubes." Int. J. Impact Eng., vol. 4, no. 4, pp. 243-270, 1986.

(C) Korol et al.; Licensee Bentham Open.

This is an open access article licensed under the terms of the Creative Commons Attribution Non-Commercial License (http://creativecommons.org/licenses/_by-nc/3.0/) which permits unrestricted, non-commercial use, distribution and reproduction in any medium, provided the work is properly cited. 